\title{
Digestão do feno de capim-elefante anão (Pennisetum purpureum Schum. cv. Mott) sob diferentes níveis de consumo em ovinos
}

\author{
Dwarf elephant grass hay (Pennisetum purpureum Schum. cv. Mott) digestion by sheep at different levels \\ of intake
}

\author{
Jucileia Aparecida da Silva Morais ${ }^{\mathrm{I}}$ Luis Maria Bonnecarrère Sanchez* Gilberto Vilmar Kozloski \\ Lisiane Dorneles de Lima ${ }^{\mathrm{I}}$ Luiz Maurício Trevisan ${ }^{\mathrm{I}}$ Mônica Vizzotto Reffatti ${ }^{\mathrm{I}}$ \\ Rui Luiz Cadorin Júnior ${ }^{\mathrm{I}}$
}

\section{RESUMO}

Foram utilizados doze ovinos Texel $\times$ Corriedale machos, castrados, com 12 meses de idade e peso vivo (PV) inicial médio de $27 \mathrm{~kg}$, mantidos em gaiolas de metabolismo, em um delineamento inteiramente casualizado, conduzido em dois períodos, para avaliar o efeito do nível de consumo (base matéria seca (MS)) de feno de capim elefante anão (CEA) $(1,50 ; 1,75 ; 2,00 ; 2,25 ; 2,50 \%$ do PV e ad libitum) sobre a digestão nesses animais. A digestibilidade aparente da MS, da matéria orgânica (MO) e do nitrogênio $(N)$, bem como a digestibilidade verdadeira do $N$, o teor de nutrientes digestíveis totais e a síntese de proteína microbiana ruminal não foram afetados, mas a retenção de $\mathrm{N}$ (em g dia $\mathrm{er}^{-1}$ e como \% do $\mathrm{N}$ consumido) foi sempre positiva e aumentou linearmente $(P<0,01)$ com o aumento do consumo de CEA. No entanto, o aumento do consumo diminuiu linearmente a digestibilidade da fibra em detergente neutro (FDN), da fibra em detergente ácido (FDA) $(P<0,05)$ e a digestibilidade verdadeira da $M O$ $(P<0,01)$. A taxa de passagem e o tempo de retenção no cecocólon não foram afetados, mas a taxa de passagem da digesta pelo retículo-rúmen aumentou e o tempo de retenção das partículas no retículo-rúmen (TRrr) e no trato digestivo total diminuiu (TRT) $(P<0,05)$ com o aumento no consumo de feno. A redução do tempo de retenção do alimento no retículorúmen diminuiu a digestibilidade verdadeira da matéria orgânica e da parede celular da forragem. No entanto, não influenciou a digestibilidade aparente da matéria orgânica e, desse modo, não influenciou o valor energético da forragem.

Palavras-chave: digestibilidade, retenção de nitrogênio, síntese de proteína microbiana, gramínea tropical, valor nutricional.

\section{ABSTRACT}

Twelve one year old Texel x Corriedale castrated male sheep, with $27 \mathrm{~kg}$ mean live weight $(L W)$, housed in metabolic cages, were used in a completely randomized experiment, carried out in two periods, to evaluate the effect of level of intake (dry matter (DM) basis) of dwarf elephant grass (1.5; $1.75 ; 2.0 ; 2.25 ; 2.5 \%$ of $L W$ and ad libitum) on digestion. $D M$, organic matter (OM) and nitrogen $(N)$ apparent digestibility, as well as the $N$ true digestibility, total digestible nutrients (TDN) contents and rumen microbial protein synthesis were not affected by level of hay intake. $N$ retention (as $g$ day ${ }^{-1}$ and as \% of $N$ intake) was always positive and increased linearly $(P<0.05)$ as the level of hay intake increased. However, neutral $(N D F)$ and acid detergent fiber ( $A D F)$ apparent digestibility, as well as $\mathrm{OM}$ true digestibility decreased linearly $(P<0.05)$ with increasing intake. Passage rate and mean retention time in the cecum-colon were not affected, whereas passage rate through the reticulum-rumen increased and mean retention time decreased $(P<0.05)$ as the level of intake increased. Fibre and $O M$ true digestibility decreased as hay intake increased $(P<0.05)$, mainly due to a decreasing in retention time of particles into the reticulo-rumen. However, OM apparent digestibility and, thus, the energetic value of dwarf elephant grass hay was not affected by the level of intake.

Key words: digestibility, nitrogen retention, microbial protein synthesis, tropical grass, nutritional value.

\section{INTRODUÇÃO}

A qualidade nutricional de uma forragem depende da digestibilidade, da eficiência de utilização dos nutrientes digeridos e absorvidos e, principalmente, do consumo voluntário. O aumento do consumo de alimento normalmente aumenta a taxa de passagem da digesta pelo trato digestivo e diminui a sua digestibilidade (VAN SOEST et al., 1992; FAICHNEY, 1993). MERTENS \& ELY (1982) consideram que grande parte da variação na digestibilidade observada entre

${ }^{1}$ Departamento de Zootecnia, Universidade Federal de Santa Maria (UFSM), Santa Maria, RS, Brasil, 97105-900. Email: bonne@smail.ufsm.br. *Autor para correspondência. 
as forrageiras pode ser atribuída a diferenças associadas à cinética da digestão. Os sistemas nutricionais, em geral, têm estabelecido fatores de desconto para estimar a digestibilidade das dietas, quando consumidas acima do nível de mantença, e sistemas mais recentes, como o Cornell Net Carbohydrate and Protein System (CNCPS), estimam a digestibilidade dos alimentos com base nas suas taxas de degradação e de passagem pelo rúmen (CANNAS et al., 2004). No entanto, os efeitos associativos entre consumo, passagem e digestibilidade parecem variar entre os alimentos (VAN SOEST, 1994). KOZLOSKI et al. (2003), por exemplo, forneceram feno de capim elefante anão para bovinos a um nível de consumo de 1,7\% do peso vivo (base matéria seca) e observaram que a taxa de passagem das partículas pelo rúmen aumentou curvilinearmente, mas a digestibilidade aparente não foi influenciada pelo aumento da idade de rebrota da forragem. Além disso, o uso dos sistemas nutricionais mais mecanísticos necessitam de caracterização detalhada dos alimentos e dos processos de digestão, a qual ainda é deficiente para forrageiras tropicais (TEDESCHI et al., 2002).

Deste modo, o presente trabalho foi conduzido com o objetivo de determinar o quanto o nível de consumo influencia a digestibilidade, a cinética da digestão, a síntese de proteína microbiana e a utilização do nitrogênio por ovinos alimentados com feno de capim elefante anão.

\section{MATERIAL E MÉTODOS}

Foram utilizados doze ovinos Texel $x$ Corriedale machos, castrados, com 12 meses de idade e peso vivo (PV) inicial médio de $27 \mathrm{~kg}$ (desvio padrão $\pm 3 \mathrm{~kg}$ ), para avaliar o efeito do nível de consumo do feno de capim elefante anão sobre sua digestão.O experimento foi conduzido com os animais mantidos em gaiolas de metabolismo, em um delineamento inteiramente causalizado, com repetição no tempo, de modo a se obter quatro repetições por tratamento. Em cada período, os animais foram alocados aleatoriamente a cada tratamento. Os níveis de consumo testados (base matéria seca (MS)) foram: 1,5; 1,75; 2,00; 2,25\% do PV e ad libitum. O feno foi picado num moinho de facas sem peneira, fragmentando o material em partículas de 5 a $15 \mathrm{~cm}$, e fornecido duas vezes ao dia, às $08 \mathrm{~h}$ e às $16 \mathrm{~h}$, misturado com aproximadamente $1 \%$ (base MS) de suplemento mineral comercial contendo, por kg: Ca: 100g, P: 45g, S: 4.12g, Na: 205g, Co: 25mg, Cu: 450mg, Fe: 1500mg, I: 50mg, Mn: 1000mg, Se: 9mg, Zn: 2520mg e F: 450mg. A oferta de feno no tratamento ad libitum foi feita de modo a permitir sobras no cocho em torno de 10 a $15 \%$ do oferecido. As sobras foram pesadas, amostradas, secadas em estufa a $55^{\circ} \mathrm{C}$, moídas (peneira com porosidade de $1 \mathrm{~mm}$ ) e armazenadas para posterior análise.

Após um período pré-experimental de aproximadamente 14 dias, em que os animais foram adaptados ao feno e às instalações, o experimento foi conduzido em dois períodos de 23 dias, sendo os 13 primeiros dias de cada período para adaptação às dietas, e os 10 dias seguintes para coleta de dados e de amostras. Para medida da digestibilidade, foi feito a coleta total das fezes em bandejas inoxidáveis instaladas sob as gaiolas, diariamente, do $14^{\circ}$ ao $18^{\circ}$ dia de cada período experimental. As fezes foram pesadas, homogeneizadas e amostradas. Estas amostras, assim como as amostras do alimento e das sobras, foram secadas a aproximadamente $55^{\circ} \mathrm{C}$, durante pelo menos $72 \mathrm{~h}$, moídas (peneira com porosidade de $1 \mathrm{~mm}$ ) e armazenadas para posterior análise. Nesse período, também foi feito a coleta total da urina em recipientes de plástico contendo $100 \mathrm{ml}$ de uma solução de ácido sulfúrico 7,2N, medido o volume e coletado uma amostra ( $1 \%$ do volume total). As amostras de urina foram colocadas em um balão volumétrico de $50 \mathrm{ml}$, completado o volume com água destilada e armazenadas em congelador (aproximadamente $-20^{\circ} \mathrm{C}$ ) para posterior análise. Para análise, as amostras de sobras, fezes e urina foram compostas de forma a obter uma amostra representativa dos cinco dias de coleta de cada animal em cada período experimental. Nas amostras das sobras, do feno e de fezes, foi determinado o teor de MS por secagem em estufa a $105^{\circ} \mathrm{C}$ durante pelo menos 8 horas, e o de cinzas por queima em mufla a $550^{\circ} \mathrm{C}$, durante aproximadamente duas a três horas. $\mathrm{O}$ teor de nitrogênio (N) total foi determinado por um método Kjeldahl (AOAC, 1995, método 984.13), modificado conforme KOZLOSKI et al. (2003). O teor de extrato etéreo (EE) foi determinado por tratar a amostra com éter etílico em sistema de refluxo, a $180^{\circ} \mathrm{C}$, durante duas horas (Soxtherm, Gerhardt, Germany). O teor de fibra em detergente neutro (FDN) foi determinado de acordo com ROBERTSON \& VAN SOEST (1981), sendo feito sem uso de amilase ou sulfito de sódio. Os teores de $\mathrm{N}$ insolúvel em detergente neutro (NIDN) e de N solúvel em tampão foram analisados de acordo com LICITRA et al. (1996). Os carboidratos totais (CHO) foram calculados como: $\mathrm{CHO}=\mathrm{MO}-((\mathrm{N} \times 6,25)+\mathrm{EE})$. Os carboidratos não-estruturais (CNE) foram calculados como: $\mathrm{CNE}=\mathrm{MO}-((\mathrm{FDN}-(\mathrm{NIDN}(6,25))+(\mathrm{N}(6,25)+$ EE), conforme VAN SOEST et al. (1991).

As digestibilidades verdadeiras da $\mathrm{MO}$ (DVMO) e do N (DVN) foram estimadas conforme 
MULLIGAN et al. (2001), considerando que somente a fração FDN das fezes é residual do alimento (VAN SOEST, 1994).

Nas amostras de urina, foi determinado o teor de $\mathrm{N}$ total, como descrito acima, e os teores de alantoína e ácido úrico, conforme CHEN \& GOMES (1995). Os teores de ácido úrico foram determinados após a conversão da xantina e da hipoxantina em ácido úrico pela xantina oxidase. A síntese de proteína microbiana ruminal foi calculada com base na excreção urinária de purinas de acordo com CHEN \& GOMES (1995).

A estimativa dos parâmetros da cinética de passagem da fase sólida da digesta ao longo do trato gastrintestinal foi feita utilizando-se fibra cromomordente (FCM), preparada conforme UDÉN et al. (1980). Aproximadamente 15 gramas de FCM (contendo entre 6 a $8 \%$ de cromo) foram fornecidas aos animais antes da alimentação matinal do $19^{\circ}$ dia de cada período experimental. A seguir, foram coletadas amostras de fezes diretamente do reto nos tempos $0,6,12,18,24,30$, 33, 36, 39, 42, 48, 54, 60, 72, 96, 120 e 144 horas após a ingestão da fibra mordente. A estimativa da taxa de passagem foi realizada somente nos animais dos tratamentos com consumo de 1,50; 2,00; 2,50\% do PV e ad libitum. Essas amostras de fezes foram submetidas à digestão ácida para solubilização do cromo conforme WILLIANS et al. (1962), e o cromo foi determinado em espectrofotômetro de absorção atômica. As variáveis da cinética de passagem foram estimadas através da análise das curvas individuais de excreção fecal de cromo, de acordo com o modelo matemático de GROVUM \& WILLIANS (1973). Os valores dos diferentes parâmetros do modelo foram calculados pelo processo iterativo do algoritmo Marquardt, com o auxílio do procedimento PROC NLIN do SAS (1996).

Os dados foram submetidos à análise de variância, que incluiu no modelo os efeitos dos tratamentos, dos períodos e da interação tratamento $\times$ período, além do erro experimental. O efeito dos tratamentos foi analisado por regressão, testando-se os efeitos linear, quadrático e cúbico. As análises foram efetuadas utilizando-se o procedimento GLM do programa estatístico SAS (1996).

\section{RESULTADOS E DISCUSSÃO}

Na tabela 1, são apresentados os resultados de variação do PV, do consumo e da digestibilidade dos compostos não-nitrogenados pelos ovinos nos diferentes níveis de consumo propostos. Os consumos de MS obtidos foram geralmente mais altos que os propostos no início do experimento devido à perda de peso dos animais no decorrer do período experimental, principalmente nos menores níveis de consumo.

O aumento do consumo de CEA não influenciou a digestibilidade aparente da MS e da MO,

Tabela 1 - Variação do peso vivo (PV), do onsumo e da dizestbilidade dos compostos rão-ritrogenados do feno de capim elefante año fomecido a diferentes níveis de oferta para ovinos.

\begin{tabular}{|c|c|c|c|c|c|c|c|c|}
\hline \multicolumn{9}{|c|}{ Hível de oferta de MS (\% do PV) } \\
\hline & 1,50 & 1,75 & $2, \infty$ & 2,25 & 2,50 & $A d i b$ & $\mathrm{DP}^{3}$ & $\mathrm{P}^{4}$ \\
\hline Variação do $\mathrm{PV}^{5}$ & $-2,9$ & -19 & $-0,8$ & $-0,5$ & 1,0 & 1,3 & 0,2 & $* *$ \\
\hline \multicolumn{9}{|c|}{ Consumo (g dia $)$ : } \\
\hline$M S$ & 438 & 503 & 565 & 599 & 702 & 927 & 2,0 & $* *$ \\
\hline MO & 388 & 447 & 501 & 533 & 625 & 821 & 9,6 & $* *$ \\
\hline FDH & 325 & 374 & 419 & 445 & 521 & 679 & 9,8 & $* *$ \\
\hline CMS (\%do PV) & 1,65 & 1,89 & 2,09 & 2,40 & 2,57 & 3,16 & 0,2 & $* * *$ \\
\hline \multicolumn{9}{|c|}{ Dizestbilidade (\% do consumo): } \\
\hline $\mathrm{MS}$ & 57,9 & 58,1 & 58,0 & 57,4 & 58,3 & 57,3 & 4,0 & $n$ \\
\hline Mo & 60,1 & 59,9 & 60,3 & 612 & 60.0 & 60,3 & 3,0 & $n$ \\
\hline FDN & 65,1 & 63,4 & 63,3 & 60,5 & 62,2 & 59,4 & 6,0 & $*$ \\
\hline $\mathrm{DVMO}^{6}$ & 67,0 & 65,4 & 65,2 & 62,4 & 64,1 & 61,4 & 6,0 & ***: \\
\hline HDT $(\% \text { na MS })^{7}$ & 54,4 & 55,1 & 56,3 & 54,3 & 55,0 & 55,1 & 4,7 & $n$ \\
\hline
\end{tabular}

MS, matéria seca; MO, matéria orgânica; FDH, fibra em detergente neutro; $\mathrm{CMS}$, consumo de MS.

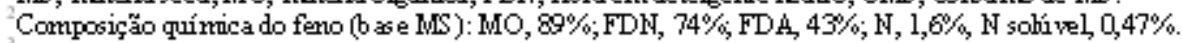

Desvio padrão d $x$ médi $x$, onde $n=4$ por tatamento.

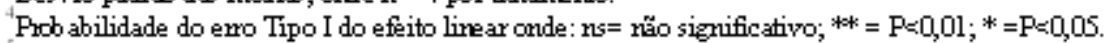

PV final $(\mathrm{kg})$ - PV inicial $(\mathrm{kg})$.

Dizes tbilidade verdadeira da MO (DVMO (\%)= ((consumo de MO (g/dia) - FDV fecal (g/dia)) / consumo de MO (g/dia) $\times 100$.

"Th triertes dizestiveis totais (calculados como a soma dos carboidratos totais, da proteína bruta do extrato etéreo dizestíveis, sendo este último multiplicado por 2,25). 
mas reduziu linearmente a digestibilidade da FDN $(\mathrm{P}<0,05)$ e a DVMO $(\mathrm{P}<0,01)$. A redução na digestibilidade da fibra não foi suficiente para influenciar o teor de NDT do feno, que foi similar em todos os níveis de consumo, mas reduziu a DVMO. Normalmente, o aumento no consumo de MS tem efeito negativo sobre a digestibilidade do alimento, mas a amplitude desse efeito parece ser maior em dietas contendo concentrado do que naquelas baseadas em volumoso (ROBINSON et al., 1987; GALYEAN \& OWENS, 1991; DOREAU \& DIAWARA, 2003). Além disso, em animais consumindo dietas à base de volumoso, o efeito do nível de consumo sobre a digestibilidade do alimento se dá, principalmente, sobre a parede celular (VAN SOEST, 1994; OSPINA \& PRATES, 1998). A intensidade deste efeito, contudo, depende da extensão da lignificação e da taxa de degradação ruminal da fibra (LONG et al., 2004). Sendo assim, quanto mais digestível a parede celular, maior o potencial de depressão da sua digestibilidade com o aumento do nível de consumo.

Os animais tiveram 73, 82, 87, 89, 102 e 130\% das suas exigências de energia metabolizável e 91, 102, 106, 108, 118 e 139\% das necessidades de proteína metabolizável para mantença supridas nos diferentes níveis de consumo observados, quando estimados pelo CNCPS (CANNAS et al., 2004). Na maioria das situações de produção, a limitação do desempenho de animais recebendo gramíneas tropicais tem sido associada à deficiências no consumo de proteína bruta. No entanto, o primeiro limitante do ganho de peso dos animais no presente trabalho foi o consumo de energia, o qual foi suficiente para manter o peso somente quando os animais consumiram acima de 2,50\% do PV de MS. Embora a digestibilidade do $\mathrm{N}$ não tenha sido influenciada, a sua retenção foi positiva em todos os tratamentos e aumentou linearmente com o aumento do consumo do feno $(\mathrm{P}<0,01)$ (Tabela 2).

A retenção de $\mathrm{N}$ aumentou provavelmente devido ao aumento simultâneo do consumo de $\mathrm{N}$ e de MO digestível. Nessa situação, além de aumentar a quantidade de aminoácidos absorvidos, diminui a sua oxidação e a sua utilização como fonte de energia nos tecidos do animal.

A síntese protéica microbiana ruminal é diretamente proporcional à quantidade de MO degradada no rúmen, desde que a disponibilidade de N às bactérias não seja limitante (CLARK et al., 1992). Além disso, a eficiência desse processo tende a aumentar com o aumento do consumo e da taxa de passagem da digesta pelo rúmen (ROBINSON et al., 1987; OWENS \& GOESTCH, 1986). No presente experimento, em valores absolutos, a eficiência da síntese microbiana do tratamento $2,50 \%$ foi bem inferior à dos demais tratamentos. No entanto, os valores médios de todos os tratamentos foram relativamente baixos e com alto coeficiente de variação. Desse modo, essas variáveis não foram influenciadas

Tabela 2 - Consumo, digestibilidade e retenção de nitrogênio $(\mathrm{N})$ e síntese de proteína microbiana ruminal em ovinos recebendo diferentes níveis de oferta de feno de capim elefante anão.

\begin{tabular}{|c|c|c|c|c|c|c|c|c|}
\hline & \multicolumn{6}{|c|}{ Nível de oferta de MS (\% do PV) } & \multirow[b]{2}{*}{$\mathrm{DP}^{1}$} & \multirow[b]{2}{*}{$\mathrm{P}^{2}$} \\
\hline & 1,50 & 1,75 & 2,00 & 2,25 & 2,50 & Ad lib & & \\
\hline Consumo(g dia $\left.{ }^{-1}\right)$ & 6,7 & 7,7 & 8,7 & 9,2 & 10,8 & 15,1 & 0,7 & ** \\
\hline \multicolumn{9}{|c|}{ Digestibilidade aparente (\%): } \\
\hline & 52,9 & 52,6 & 50,1 & 50,2 & 51,2 & 51,9 & 3,0 & ns \\
\hline \multicolumn{9}{|c|}{ Digestibilidade verdadeira $(\%)^{3}$ : } \\
\hline & 86,6 & 84,1 & 86,0 & 84,9 & 85,1 & 86,0 & 1,0 & ns \\
\hline \multicolumn{9}{|l|}{ Retenção $\left(\mathrm{g} \mathrm{dia}^{-1}\right)$ : } \\
\hline & 0,39 & 0,41 & 1,28 & 1,05 & 2,08 & 3,40 & 0,2 & $* *$ \\
\hline \multicolumn{9}{|c|}{ Retenção (\% do N consumido): } \\
\hline & 5,4 & 5,5 & 15,6 & 10,7 & 19,0 & 22,3 & 3,0 & $* *$ \\
\hline \multicolumn{9}{|c|}{ Síntese de proteína microbiana ruminal (g de N microbiano dia $^{-1}$ ): } \\
\hline & 2,3 & 3,0 & 2,4 & 2,9 & 1,7 & 4,4 & 1,5 & ns \\
\hline \multicolumn{9}{|c|}{ Eficiência microbiana ruminal (g N microbiano kg MO verdadeiramente digestível ${ }^{-1}$ ): } \\
\hline & 8,9 & 10,0 & 7,1 & 9,1 & 4,0 & 8,8 & 4,0 & ns \\
\hline
\end{tabular}

${ }^{1}$ Desvio padrão das médias, onde $\mathrm{n}=4$ por tratamento.

${ }^{2}$ Probabilidade do erro Tipo I do efeito linear onde: ns= não significativo; ** $=\mathrm{P}<0,01 ; *=\mathrm{P}<0,05$.

${ }^{3}($ consumo de $\mathrm{N}$ (g/dia) - N insolúvel em detergente neutro fecal $(\mathrm{g} / \mathrm{dia})) /$ consumo de $\left.\mathrm{N}\right) \times 100$. 
significativamente pelo aumento do consumo de feno (Tabela 2). Se, por um lado, o consumo de energia pelos animais foi predominantemente na forma de carboidratos de lenta digestão ruminal, por outro, a proporção de $\mathrm{N}$ solúvel em relação ao $\mathrm{N}$ total do feno foi relativamente alta (em torno de 30\%). Estes compostos nitrogenados são prontamente degradados no rúmen e, desse modo, é provável que a falta de sincronia na disponibilidade de amônia e carboidratos tenha limitado o crescimento das bactérias ruminais. Adicionalmente, a síntese microbiana foi estimada com base na excreção urinária dos derivados de purinas, considerando que parte deles é de origem microbiana e outra de origem endógena. É possível que este método superestime a excreção endógena dos derivados de purinas e, deste modo, subestime a síntese de proteína microbiana ruminal em condições em que o consumo de alimento e o crescimento microbiano sejam limitados. Esta hipótese, contudo, necessita ser testada.

A taxa de passagem e o tempo de retenção no ceco-cólon não foram influenciados pelos tratamentos, mas a taxa de passagem da fase particulada da digesta pelo retículo-rúmen aumentou linearmente $(\mathrm{P}<0,01)$ e, conseqüentemente, os tempos de retenção no retículo-rúmen e no trato digestivo total diminuíram linearmente $(\mathrm{P}<0,01)$ com o aumento do nível de consumo de feno (Tabela 3). Relação direta entre consumo e passagem tem sido observada em vários experimentos (COLUCCI et al., 1982; OKINE \& MATHISON, 1991; LUGINBHUL et al., 1994; OSPINA \& PRATES, 1998). Os valores de taxa de passagem pelo retículo-rúmen foram similares aos estimados pelo CNCPS (CANNAS et al., 2004) para ovinos alimentados com feno semelhante ao utilizado no presente trabalho (3,02, 3,31, 3,57 e 4,06 \% $\mathrm{h}^{-1}$ para os níveis 1,50, 2,00, 2,50 e ad libitum, respectivamente).
A magnitude da digestão de qualquer alimento é função da taxa de degradação e do tempo que permanece exposto à atividade microbiana ruminal (MERCHEN, 1988; DOREAU \& DIAWARA, 2003). A parede celular é a fração de mais lenta degradação da forragem. Dessa forma, todos os fatores que diminuam o tempo de retenção ruminal provocam uma diminuição da digestibilidade da parede celular e, conseqüentemente, aumenta a perda fecal de parede celular potencialmente digestível (MINSON, 1990). De fato, no presente trabalho, a digestibilidade da FDN, assim como a DVMO, foram inversamente relacionadas ao aumento do consumo e à taxa de passagem da digesta pelo retículo-rúmen. Contudo, a digestibilidade média da FDN foi relativamente alta (em torno de 62\%). Têm sido reportadas na literatura taxas de degradação da FDN do capim elefante de até $7 \% \mathrm{~h}^{-1}$ (CABRAL et al., 2000) e, deste modo, mesmo no tratamento ad libitum o tempo de retenção ruminal das partículas (17h) pode ter sido suficiente para possibilitar alta degradação desta fração.

\section{CONCLUSÕES}

O aumento no consumo diminuiu a digestibilidade verdadeira da matéria orgânica e da fibra do feno de capim elefante anão como conseqüência de uma maior taxa de passagem e de um menor tempo de retenção do alimento no retículo-rúmen. No entanto, não influenciou a digestibilidade aparente da matéria orgânica e, desse modo, diferentemente do proposto pelos sistemas nutricionais, não influenciou o valor energético da forragem.

Tabela 3 - Taxa de passagem da fáe sólida da dizesta pelo retícub-rúmen (TPr) e pelo ceoo-cólon (TPcc) e tempo de reterção no retículońmen (TRrr), no oco-ólon (TRcc) e no trato gastintes tinal total (TRT) em ovinos recebendo diferentes rúveis de oferta de feno de capim elefarte amõo.

\begin{tabular}{|c|c|c|c|c|c|c|}
\hline & \multicolumn{4}{|c|}{ Hível de oferta de MS (\% do PV) } & \multirow[b]{2}{*}{$\mathrm{DP}$} & \multirow[b]{2}{*}{$\mathrm{P}^{2}$} \\
\hline & 1,50 & 2,00 & 2,50 & Ad L.jb & & \\
\hline $\operatorname{TPr}\left(\% \mathrm{~h}^{-1}\right)$ & 3,0 & 3,6 & 3,7 & 5,9 & 0,6 & ***; \\
\hline TPoc $\left(\% \mathrm{~h}^{-1}\right)$ & 7,5 & 8,9 & 15,0 & 10,6 & 3,0 & $\mathrm{rs}$ \\
\hline $\operatorname{TRm}^{3}$ & 34,6 & 29,3 & 27,8 & 17,5 & 5,0 & *** \\
\hline TRcc $^{4}$ & 14,0 & 12,4 & 7,8 & 9,6 & 3,0 & $*$ \\
\hline TRT & 62,8 & 5,3 & 46,4 & 38,5 & 4,5 & *** \\
\hline
\end{tabular}

Desvio padrăo das médias, onde $n=4$ por tratamento.

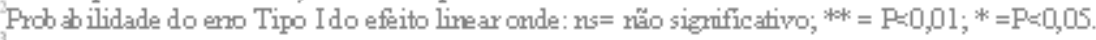

$\operatorname{TRn}($ horas $)=1 / k$

TRec(horas) $=1 / k$

TRThors) $=$ TT + TRry + TRcc, sendo TT o tertwo (horas) para o primeino aparecimerto de cromo nas fezes 


\section{REFERÊNCIAS}

AOAC - Association of Official Analytical Chemists. Official methods of analysis. Washington, 1995. 1094p.

CABRAL, L.S. et al. Frações de carboidratos de alimentos volumosos e suas taxas de degradação estimadas pela técnica de produção de gases. Revista Brasileira de Zootecnia, v.29, p.2087-2098, 2000.

CANNAS, A. et al. A mechanistic model to predict nutrient requirements and feed biological values for sheep in each unique production situation. Journal of Animal Science, v.82, p.149-169, 2004

CHEN, X.B.; GOMES, M.J. Estimation of microbial protein supply to sheep and cattle based on urinary excretion of purine derivatives - An overview of the technical details. Bucksburn Aberdeen: Rowett Research Institute, 1995. 21p. (Occasional Publication).

CLARK, J.H. et al. Microbial protein synthesis and flows of nitrogen fractions to the duodenum of dairy cows. Journal of Dairy Science, v.75, p.2304-2323,1992.

COLUCCI, P.E. et al. J. Feed intake, apparent diet digestibility and rate of particulate passage in dairy cattle. Journal of Dairy Science, v.65, p.1445-1456, 1982.

DOREAU, M.; DIAWARA, A. Effect of level of intake on digestion in cows: influence of animal genotype and nature of hay. Livestock Production Science, v.81, p.35-45, 2003.

FAICHNEY, G.J. Digesta flow. In: FORBES, J.M.; FRANCE, J. Quantitative aspects of ruminants digestion and metabolism. Wallingford: CAB International, 1993. p.53-85.

GALYEAN, M.L.; OWENS, F.N. Effects of diet composition and level of feed intake on site and extent of digestion in ruminants. In: TSUDA, T. et al. Physiological aspects of digestion and metabolism in ruminants. San Diego: Academic, 1991. p.483-512.

GROVUM, W.L.; WILLIANS, V.J. Rate of passage of digesta in sheep. IV. Passage of marker through the alimentary tract and the biological relevance of rate constants derived from the changes in concentration of marker in feces. British Journal of Nutrition, v.30, p.313-329, 1973.

KOZLOSKI, G. V. et al. Potential nutritional assessment of dwarf elephant grass by chemical composition, digestion and net portal flux oxigen in cattle. Animal Feed Science and Techonology, v.104, p.29-40, 2003

LICITRA, G. et al. Standartization of procedures for nitrogen fractionation of ruminant feeds. Animal Feed Science and Technology, v.57, p.347-358, 1996.

LONG, R.J. et al. Digestibility, nutrient balance and urinary purine derivative in dry yak cows fed oat hay at different levels of intake. Livestock Production Science, v.88, p.27-32, 2004.

LUGINBUHL, J.M. et al. Whole-tract digesta kinetics and comparison of techniques for the estimation of fecal output in steers fed coastal bermudagrass hay at four levels intake. Journal of Animal Science, v.72, p.201-211, 1994.
MERCHEN, N.R. Digestión, absorción y excreción en los rumiantes. In: $\mathrm{CHURCH}$, D.C. El rumiante: fisiología digestiva y nutrición. Zaragoza: Acribia, 1988. p.191-224.

MERTENS, D.R.; ELY, O.L. Relationship of rate and extent of digestion to forage utilization - A dynamic model evaluation. Journal of Animal Science, v.54, p.895-905, 1982.

MINSON, D.J. Forage in ruminant nutrition. San Diego: Academic, 1990. 483p.

MULLIGAN, F.J. et. al. The effect of dietary protein content and hay intake level on the true and apparent digestibility of hay. Livestock Production Science, v.68, p.41-52, 2001.

OKINE, E.K.; MATHISON, G.W. Effects of feed intake on particle distribution, passage of digesta and extent of digestion in the gastrointestinal tract of cattle. Journal of Animal Science, v.69, p.3435-3445, 1991.

OSPINA, H.P.; PRATES, E.R. Efeito de quatro níveis de feno sobre o consumo de nutrientes digestíveis por bezerros. Revista Brasileira de Zootecnia, v.27, p.809-814, 1998.

OWENS, F.N.; GOETSCH, A.L. Digesta passage and microbial protein synthesis. In: MILLIGAN, L.P. et al. Control of digestion and metabolism in ruminants. Englewood Cliffs: Prentice Halls, 1986. p.285-306.

ROBERTSON, J.B.; VAN SOEST, P.J. The detergent system of analysis. In: JAMES, W.P.T.; THEANDER, O. The analysis of dietary fibre in food. New York: Marcel Dekker, 1981. Chap.9, p.123-158.

ROBINSON, P.H. et al. Influence of declining level of feed intake and varying the proportion of starch in the concentrate on milk production and whole tract digestibility in dairy cows. Livestock Production Science, v.17, p.19-35, 1987.

SAS. Statistical Analysis Systems Institute. SAS user's guide. Version 6.08. Cary: Analysis System Institute, 1996. 1041p.

TEDESCHI, L.O. et al. Development and evaluation of a tropical feed library for the Cornell Net Carbohydrate and Protein System model. Scientia Agricola, v.59, p.1-18, 2002.

UDÉN, P. et al. Investigation of chromium, cerium and cobalt as markers in digesta: rate of passage studies. Journal of the Science of Food and Agriculture, v.31, p.625-632, 1980

VAN SOEST, P.J. Nutritional ecology of the ruminant. 2.ed. New York: Cornell University, 1994. 476p.

VAN SOEST, P.J. et al. Methods for dietary fiber, neutral detergent fiber and nonstarch polysaccharides in relation to animal nutrition. Journal of Dairy Science, v.74, p.35833597, 1991

VAN SOEST, P.J. et al. Discounts for net energy and protein, fifth revision. In: CORNELL NUTRITION CONFERENCE, 1992, Ithaca, New York. Proceedings... Ithaca: Cornell University, 1992. p.40-68.

WILLIANS, C.H. et al. The determination of chromic oxide in faeces samples by atomic absorption spectrophotometry. Journal of Animal Science, v.59, p.381-385, 1962. 